\title{
Article
}

\section{Trends of Perinatal Stress, Anxiety, and Depression and Their Prediction on Postpartum Depression}

\author{
Ching-Yu Cheng ${ }^{1,2}{ }^{\oplus}$, Yu-Hua Chou ${ }^{3}$, Chia-Hao Chang ${ }^{1}$ and Shwu-Ru Liou ${ }^{1,2, *}$ \\ 1 College of Nursing, Chang Gung University of Science and Technology, Puzi City 61363, Taiwan; \\ cycheng@mail.cgust.edu.tw (C.-Y.C.); chchang@mail.cgust.edu.tw (C.-H.C.) \\ 2 Chiayi Chang Gung Memorial Hospital, Puzi City 61363, Taiwan \\ 3 Department of Nursing, Cardinal Tien Junior College of Healthcare and Management, \\ Yilan County 26646, Taiwan; chouyuhua57@gmail.com \\ * Correspondence: srliou5022@mail.cgust.edu.tw
}

check for

updates

Citation: Cheng, C.-Y.; Chou, Y.-H.; Chang, C.-H.; Liou, S.-R. Trends of Perinatal Stress, Anxiety, and Depression and Their Prediction on Postpartum Depression. Int. J. Environ. Res. Public Health 2021, 18, 9307. https://doi.org/10.3390/ ijerph18179307

Academic Editors: Mariola Bidzan, Łucja Bieleninik and Karolina Lutkiewicz

Received: 28 July 2021

Accepted: 30 August 2021

Published: 3 September 2021

Publisher's Note: MDPI stays neutral with regard to jurisdictional claims in published maps and institutional affiliations.

Copyright: (c) 2021 by the authors. Licensee MDPI, Basel, Switzerland. This article is an open access article distributed under the terms and conditions of the Creative Commons Attribution (CC BY) license (https:// creativecommons.org/licenses/by/ $4.0 /)$.

\begin{abstract}
Perinatal stress, anxiety, and depression impacts not only women but also their child(ren). The purpose of this longitudinal study is to explore trends of stress, anxiety, and depressive symptoms from pregnancy to postpartum and understand predictions of stress and anxiety on postpartum depression. One-hundred-fifty-six women at 23-28 weeks gestation (T1), 147 at 32-36 weeks gestation (T2), 129 at over 36 weeks gestation (T3), and 83 at postpartum (T4) completed study surveys. The Perceived Stress Scale, Center for Epidemiologic Studies Depression scale, and State-Trait Anxiety Inventory were used to measure stress, depressive symptoms, and anxiety. Descriptive statistics, Pearson and Spearman's correlation, and Generalized Estimating Equation were applied to analyze the data. Results showed that levels of anxiety and depressive symptoms increased from 24 weeks gestation to postpartum, whereas stress levels decreased during pregnancy but increased in postpartum. Over half of women experienced anxiety symptoms, especially during late pregnancy and postpartum. Stress, anxiety, and depressive symptoms were inter-correlated. Notably, women at late pregnancy and postpartum were prone to stress, anxiety, and depression. Prenatal anxiety could predict postpartum depressive symptoms. Active assessment and management of stress, anxiety, and depression is needed and should begin from early pregnancy and continue until postpartum.
\end{abstract}

Keywords: perinatal; stress; anxiety; depression; pregnancy; postpartum

\section{Introduction}

Based on a 2017 worldwide statistic, depressive disorders were among the top three leading cause of years lived with disability [1]. Compared with men, women have a higher prevalence and incidence of depression [2-4]. Specifically, during the perinatal period, women had a higher risk of developing or aggravating an underlying mental illness [5]. Systematic review and meta-analysis articles reported that pooled prevalence of depression was $7.4 \%, 12.8 \%$, and $12.0 \%$ at the first, second, and third trimester of pregnancy, respectively, and it was $17.7 \%$ at postpartum [6,7]. Yet, perinatal depression may not be recognized because of physical and psychological changes throughout pregnancy and postpartum [8]. Furthermore, only one-fourth of women who experienced moderatesevere postpartum depressive symptoms sought mental health care or consultations about their emotional or psychological problems [9]. Anxiety is another important perinatal mood disorder that needs to addressed [8] and is comorbid with depression [2,10]. A meta-analysis article reported that the prevalence of self-reported anxiety symptoms was $18.2 \%, 19.1 \%$, and $24.6 \%$ at the first, second, and third trimester, respectively, while it was $17.8 \%$ during the first postpartum month [11].

Both perinatal depression and anxiety can lead to adverse outcomes. Prenatal depressed moods were related to a lower intensity of preoccupation with and more negative affective experiences toward the fetus [12], poor self-esteem during pregnancy [13], shorter 
gestation [14], birth complications with the baby and low birth weight [14-16]. Children of mothers with postpartum depression were at risk of maltreatment and subsequent social, emotional, and behavioral problems [17]. In particular, mothers who experienced depressed moods during the first trimester or throughout pregnancy had a higher level of postpartum psychosocial difficulties than their counterparts [18], and those who had postpartum depression had infant attachment problems [19]. Regarding anxiety, a higher level of prenatal anxiety is related to a shorter pregnancy duration [20]. Pregnant women who experienced anxiety had a higher risk of having a baby with birth complications and lower Apgar scores [14]. Mothers with anxiety were less likely to breastfeed and were less likely to breastfeed for longer than 1 month [21]. Perinatal anxiety was correlated with children's social-emotional development, negative behaviors and emotions throughout the period from infancy to adolescence [19,22]. Women with untreated prenatal mood and anxiety disorders had a higher risk of suicide, preeclampsia, preterm birth, cesarean delivery, not breastfeeding or breastfeeding suboptimally [23], infant death, child behavioral and developmental disorders, obesity, asthma, and injuries [23]. However, Rees et al.'s systemic review on 14 articles found that the impacts of perinatal anxiety on the child's emotional problems were low [24]. Although maternal anxiety or depression alone has a certain degree of influence, researchers have suggested that pregnant women with comorbid depression and anxiety have a greater incidence of prematurity than the only depressed or only anxiety groups [25]. The average cost per woman with untreated mood and anxiety disorders during pregnancy and five-year postpartum in 2017 was about US $\$ 32,300$. Of this cost, over $50 \%$ occurred during pregnancy [23].

Studies have been done to explore factors related to perinatal emotional distress. Among the factors, perceived stress has been found to be related to depressive symptoms and anxiety from early pregnancy to postpartum $[26,27]$. This correlation exists not only in adults but also in late adolescents and young adults [28]. Specifically, postnatal stress predominantly explains the variance of postnatal depressive symptoms, anxiety, and parental self-efficacy [27]. Mothers who perceived higher levels of stress were at higher risk of having pregnancy complications [29,30] and preterm birth [30], were less likely to breastfeed [31], and increase disease risk of their offspring within first 7 months of life [32]. Postpartum mothers who experienced higher levels of stress reported less parental self-efficacy [27].

By understanding the trends and relationships of stress, depressive symptoms, and anxiety throughout the perinatal period, appropriate interventions can be implemented to prevent the consequent impacts of those mental distress on women and their offspring. The purpose of this study is to explore trends and relationships between perinatal depressive symptoms, anxiety, and stress and predictors of postpartum depressive symptoms. The following research questions are answered: (a) what are the trends of stress, depressive symptoms, and anxiety from pregnancy to postpartum? (b) what are the factors of postpartum depressive symptoms?

\section{Materials and Methods}

\subsection{Design}

This study is part of a prospective longitudinal study that focuses on perinatal mental distress, sleep quality, fatigue, and biomarkers. This paper reports perinatal stress, depressive symptoms, and anxiety from pregnancy to postpartum. The data were collected from May 2012 to September 2013. The participants were recruited when they were about 24 gestational weeks (T1) and were followed up at around 32 weeks gestation (T2), 36 weeks (T3), and one month postpartum (T4), with a total of four times surveyed. Because pregnant women may experience more physical symptoms during the third trimester when compared with the second trimester and the prevalence of depression remained high from the second to the third trimester whereas the prevalence of anxiety increased in the third trimester, the participants were surveyed one time in the second trimester (before 28 weeks gestation) and two times in the third trimester (after 28 weeks gestation). The time for 
postpartum survey was done after the participants were discharged from the hospital when they had to face the childcare responsibility and adjust to the new maternal role. Since new mothers would have their postnatal checkup at around 4 to 6 weeks postpartum, the survey appointment was made at that time point.

\subsection{Setting}

Participants were recruited at the obstetric clinic of two hospitals located in two metropolitan cities in northern (Taipei) and southern (Chiayi) Taiwan.

\subsection{Sample and Sampling}

Non-probability sampling was used to recruit participants. Pregnant women who were at least 18 years old, could read and write Chinese, were at about 24 weeks of gestation, were singleton, and did not have any pregnancy complications (including a diagnosis of prenatal depression or anxiety disorder) were eligible for participating in this study. The sample size was calculated using $G^{*}$ Power 3.0.10 [33]. To achieve a median effect size (.13) [34], power of $0.80, \alpha$ of 0.05 , one group, and median correlation among repeated measures $(r=0.3), 117$ pregnant women were needed. Using a longitudinal design, this study might have high attrition rate of 30\%; therefore, we needed to recruit at least 153 pregnant women.

In total, we invited 160 pregnant women who were eligible to participate, 156 of whom participated and completed the T1 survey. We lost contact with 9, 18, and 46 participants at T2, T3, and T4, respectively; therefore, 147, 129, and 83 participants remained in the study at T2, T3, and T4, respectively. Those who dropped out and remained in the study did not differ in age, parity, marital status, educational level, employment, happiness about the pregnancy, whether they planned the pregnancy, and whether they had sleep disturbances; however, they differed in gestational age at T1. Those who dropped out from the study $(\mathrm{M}=24.84, \mathrm{SD}=1.13)$ were more advanced in their pregnancy than those who participated throughout the study $(\mathrm{M}=24.49, \mathrm{SD}=0.74, \mathrm{t}=2.20, p=0.03)$. The attrition rate from $\mathrm{T} 1$ to T4 was $46.8 \%$, which was higher than our expectation. We did a post-hoc power analysis based on the lowest correlation value between measured variables ( $r=0.35$ for both T1 and T4 trait anxiety, and T1 state anxiety and T4 stress) and sample size of 83, the power was 0.91 , which meant an adequate sample size.

The mean age of the participants was $31.46(\mathrm{SD}=4.24)$ years, and the mean gestational age at $\mathrm{T} 1$ was $24.63(\mathrm{SD}=1.00)$ weeks. As shown in Table 1 , around half of the participants were primiparous and had an educational level of bachelor's degree or higher. Most of the participants were married, employed, happy about the pregnancy, had planned the pregnancy, and experienced sleep disturbances (especially interrupted sleep).

\subsection{Instruments}

Depressive symptoms. The 20-item Center for Epidemiologic Studies Depression (CESD) is a four-point (0-3) self-administered scale [35] and is used to measure depressive symptoms from prenatal to postpartum in this study. A higher score indicates a higher probability an individual is experiencing depression. A cut-off score of 16 was used to determine non-depression/depression [35]. The Chinese version of the CESD has been used with pregnant women and postpartum mothers with high Cronbach's alphas (Cronbach's alpha $=0.89$ ) [36]. The Cronbach's alpha of the CESD at T1 in this study was 0.90 .

Stress. The 10-item Perceived Stress Scale (PSS) (Supplementary S1) is a five-point (0-4) Likert-type scale that measures the level an individual appraises as stressful. The validity of the PSS was supported based on the result of a factor analysis that one factor could explain $77.5 \%$ of the total variance of stress [37]. The Chinese version of the PSS has been used to measure maternal stress with satisfactory reliability (Cronbach's alpha of 0.87) [38]. The Cronbach's alpha of the PSS at T1 in this study was 0.84. 
Table 1. Demographic information of the participants at Time $1(n=156)$.

\begin{tabular}{|c|c|c|}
\hline Variable & $n$ & $\%$ \\
\hline \multicolumn{3}{|l|}{ Parity } \\
\hline Primiparous & 83 & 53.2 \\
\hline Multiparous & 73 & 46.8 \\
\hline \multicolumn{3}{|l|}{ Marital status } \\
\hline Single & 6 & 3.8 \\
\hline Married/partnered & 148 & 94.9 \\
\hline Other & 2 & 1.3 \\
\hline \multicolumn{3}{|l|}{ Education level } \\
\hline Bachelor's or higher & 80 & 51.3 \\
\hline Lower than bachelor's & 74 & 47.4 \\
\hline Missing & 2 & 1.3 \\
\hline \multicolumn{3}{|l|}{ Employment } \\
\hline Unemployed & 39 & 25.0 \\
\hline Employed & 117 & 75.0 \\
\hline \multicolumn{3}{|l|}{ Planned pregnancy } \\
\hline No & 58 & 37.2 \\
\hline Yes & 95 & 60.9 \\
\hline Missing & 3 & 1.9 \\
\hline \multicolumn{3}{|l|}{ Happy about the pregnancy } \\
\hline Uncertain & 12 & 7.7 \\
\hline Very unhappy/unhappy & 7 & 4.5 \\
\hline Very happy or happy & 136 & 87.2 \\
\hline Missing & 1 & 0.6 \\
\hline \multicolumn{3}{|l|}{ Sleep disturbance } \\
\hline No & 45 & 28.8 \\
\hline Yes & 110 & 70.5 \\
\hline Missing & 1 & 0.6 \\
\hline \multicolumn{3}{|l|}{ Type of sleep disturbance ${ }^{1}$} \\
\hline Interrupted sleep & 78 & 73.6 \\
\hline Unable to fall asleep & 29 & 27.4 \\
\hline Lack of sleep & 12 & 11.3 \\
\hline Sleepy during daytime & 25 & 23.6 \\
\hline
\end{tabular}

${ }^{1}$ Only those who experienced sleep disturbance $(n=110)$ answered this multiple-selection question.

Anxiety. The State-Trait Anxiety Inventory (STAI) developed by Spieblerger [39] was used to measure state and trait anxiety in the study. It is a 40-item, four-point (1-4) scale that measures state anxiety (20 items, STAI-S) and trait anxiety (20 items, STAI-T). The scale score ranges from 20 to 80, with a higher score indicating a higher level of trait or state anxiety experienced by an individual. The STAI has been used to measure anxiety levels of the pregnant population with satisfactory reliability [40]. A cut-off score of 40-41 was used to determine low-high level of anxiety [41]. The STAI has been translated into Chinese and its Cronbach's alpha was high (0.90 for the STAI-S and 0.81 for the STAIT) [42]. The Cronbach's alpha for the STAI-S and STAI-T at T1 in this study was 0.88 and 0.93 , respectively.

\subsection{Procedure}

The study was conducted after an approval from the Institutional Review Board (IRB No. 101,073 and 100-2777A3). Data were collected at the obstetric clinic in hospitals while the participants were waiting for prenatal checkups. The principal investigator explained the research to the obstetricians in the two hospitals where the research team affiliated and had their permission to recruit participants in the obstetric clinic. The obstetricians and registered nurses mentioned the study to potential participants when they were having their prenatal checkups. Those who were interested in participating in the study or had questions about the study then talked with the research investigator or trained 
research assistant who stayed at the waiting area of the clinic. The research, participants' rights, confidentiality, and privacy were introduced to the participants. After agreeing and signing a consent form, participants either were interviewed or self-administered the questionnaires. Participants who preferred to complete the questionnaires at home were asked to mail the completed questionnaires to researchers using the self-addressed and stamped returning envelope within 1 week. Subsequent appointments were made after the participants had scheduled their following checkups. Participants were asked to inform the investigators when they gave birth, and another appointment for postpartum data collection was made. Phone calls were made to remind the participants of their appointments and at their due date if the participants did not inform the investigators about their labor/delivery.

\subsection{Data Analysis}

Collected data were managed and analyzed using SPSS version 23.0. The measured variables were examined for missing values and normality. The missing completely at random (MCAR), which assumes the missing value is not dependent on both observed and unobserved data, is a stronger missing data mechanism than missing at random (MAR) [43]. The Little's MCAR test is a single test developed by Little to avoid problems of multiple comparisons when testing MCAR [44]. Results showed that the STAI-S at T1 and T2, STAI-T at T1 and T4, and CESD at T2 and T4 had one missing value. Little's MCAR test showed that the data was "missing completely at random" $(\mathrm{X} 2=40.29, p=0.63)$. The expectationmaximization (EM) algorithm was used to manage missing values. The Shapiro-Wilk test showed that the PSS at T4, STAI-T at T2, and CESD at all survey times were not normally distributed. Descriptive statistics were used to understand the participants' demographic information and levels of measured variables. Pearson and Spearman's correlation was used to test relationships between measured variables. The Generalized Estimating Equation (GEE) was used to test changes of the measured variables by time period and prediction of stress and anxiety on postpartum depression.

\section{Results}

\subsection{Trends of Perinatal Stress, Depressive Symptoms, and Anxiety}

From Figure 1 and Table 2, stress levels decreased from T1 to T2 and T3 and then increased at T4. However, when compared with $\mathrm{T} 1$, the change at $\mathrm{T} 2$ was statistically significant. In addition, since the mean score of the PSS at T1 and T4 was extremely close, we inferred that stress at T4 was significantly higher than it was at T2. Trait anxiety increased from T1 to T4; yet, those changes were not statistically significant. State anxiety increased throughout pregnancy and decreased at postpartum. Levels of state anxiety at T3 were significantly higher than that at T1. Levels of depressive symptoms increased along the time from $\mathrm{T} 1$ to $\mathrm{T} 4$, and the level at $\mathrm{T} 3$ and $\mathrm{T} 4$ was significantly higher than that at $\mathrm{T} 1$.
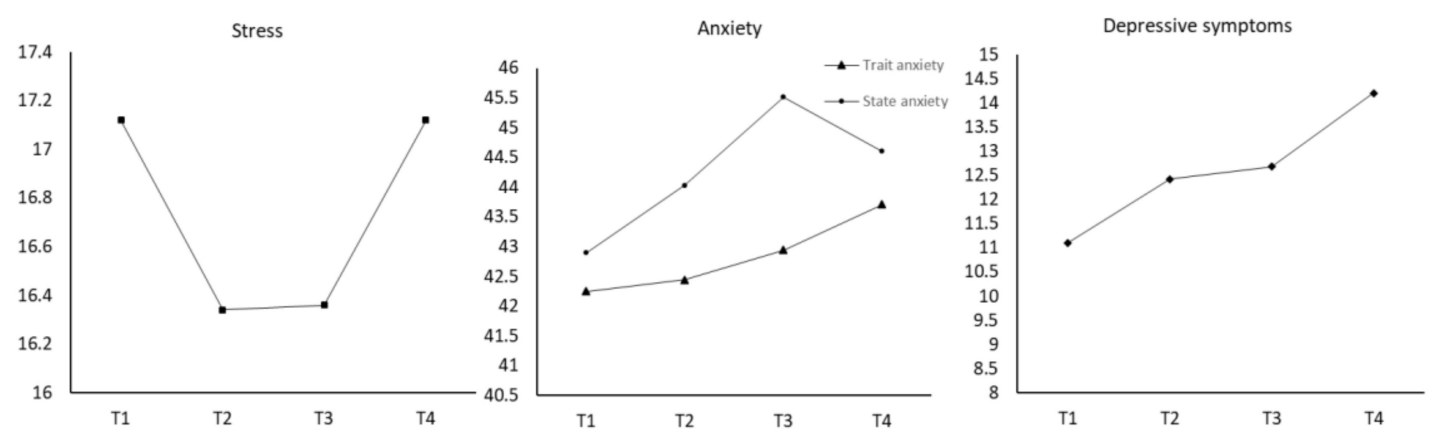

Figure 1. Longitudinal Changes of Perinatal Stress, Anxiety, and Depressive Symptoms. 
Table 2. Trends of stress, anxiety, and depressive symptoms from pregnancy to postpartum.

\begin{tabular}{|c|c|c|c|c|c|c|}
\hline Variable & $\mathbf{M} \pm \mathbf{S D}$ & B & SE & $95 \%$ CI & Wald $X^{2}$ & $p$ \\
\hline \multicolumn{7}{|l|}{ Stress } \\
\hline Intercept & & 17.12 & 0.42 & $16.30,17.94$ & 1676.52 & $<0.001$ \\
\hline $\mathrm{T} 1$ & $17.12 \pm 5.24$ & - & & & & \\
\hline $\mathrm{T} 2$ & $16.34 \pm 5.58$ & -0.85 & 0.36 & $-1.56,-0.14$ & 5.44 & 0.02 \\
\hline T3 & $16.36 \pm 5.98$ & -0.79 & 0.41 & $-1.61,0.02$ & 3.67 & 0.06 \\
\hline $\mathrm{T} 4$ & $17.12 \pm 6.52$ & 0.25 & 0.62 & $-0.98,1.47$ & 0.16 & 0.69 \\
\hline \multicolumn{7}{|l|}{ Trait anxiety } \\
\hline Intercept & & 42.25 & 0.76 & $40.67,43.73$ & 3113.60 & $<0.001$ \\
\hline $\mathrm{T} 1$ & $42.25 \pm 9.49$ & - & & & & \\
\hline $\mathrm{T} 2$ & $42.44 \pm 10.23$ & 0.10 & 0.63 & $-1.14,1.35$ & 0.03 & 0.87 \\
\hline T3 & $42.94 \pm 9.87$ & 0.49 & 0.63 & $-0.074,1.73$ & 0.61 & 0.43 \\
\hline $\mathrm{T} 4$ & $43.71 \pm 10.87$ & 1.59 & 1.12 & $-0.61,3.78$ & 2.01 & 0.16 \\
\hline \multicolumn{7}{|l|}{ State anxiety } \\
\hline Intercept & & 42.91 & 0.88 & 41.19 & 2400.89 & $<0.001$ \\
\hline $\mathrm{T} 1$ & $42.90 \pm 10.97$ & - & & & & \\
\hline $\mathrm{T} 2$ & $44.03 \pm 11.49$ & 1.03 & 0.79 & $-0.52,2.58$ & 1.71 & 0.19 \\
\hline T3 & $45.51 \pm 12.23$ & 2.38 & 0.90 & $0.62,4.15$ & 7.00 & 0.01 \\
\hline $\mathrm{T} 4$ & $44.60 \pm 11.89$ & 1.94 & 1.23 & $-0.47,4.36$ & 2.49 & 0.12 \\
\hline \multicolumn{7}{|l|}{$\begin{array}{l}\text { Depressive } \\
\text { symptoms }\end{array}$} \\
\hline Intercept & & 11.10 & 0.62 & $9.88,12.31$ & 319.09 & $<0.001$ \\
\hline $\mathrm{T} 1$ & $11.10 \pm 7.78$ & - & & & & \\
\hline $\mathrm{T} 2$ & $12.42 \pm 9.10$ & 1.21 & 0.64 & $-0.03,2.45$ & 3.65 & 0.06 \\
\hline $\mathrm{T} 3$ & $12.68 \pm 8.53$ & 1.55 & 0.66 & $0.26,2.85$ & 5.54 & 0.02 \\
\hline $\mathrm{T} 4$ & $14.20 \pm 11.01$ & 3.17 & 1.08 & $1.05,5.29$ & 8.60 & 0.003 \\
\hline
\end{tabular}

T1: 23 to 28 weeks of gestation; T2: 32 to 36 weeks of gestation; T3: over 36 weeks of gestation; T4: 4 to 6 weeks postpartum.

The percentage of women experiencing depression at $\mathrm{T} 1$ through $\mathrm{T} 4$ ranged from $25.6 \%$ to $34.9 \%$; ranged from $53.2 \%$ to $60.2 \%$ for trait anxiety; and ranged from $59.9 \%$ to $63.9 \%$ for state anxiety (Table 3). While $13.3 \%$ experienced depression at all four data collection time points, $30.1 \%$ and $34.9 \%$ of women experienced higher levels of trait anxiety and state anxiety, respectively, at all four time points. More than one fourth of women were both depressed and anxious at some point in time during pregnancy and postpartum.

Table 3. Prevalence of anxiety and depression from pregnancy to postpartum.

\begin{tabular}{|c|c|c|c|c|c|c|c|c|c|c|}
\hline \multirow[t]{2}{*}{ Variable } & \multicolumn{2}{|c|}{ T1 $(n=156)$} & \multicolumn{2}{|c|}{ T2 $(n=147)$} & \multicolumn{2}{|c|}{ T3 $(n=129)$} & \multicolumn{2}{|c|}{$\mathrm{T} 4(n=83)$} & \multicolumn{2}{|c|}{ All Four Times } \\
\hline & $n$ & $\%$ & $n$ & $\%$ & $n$ & $\%$ & $n$ & $\%$ & $n$ & $\%$ \\
\hline Depression & 40 & 25.6 & 42 & 28.6 & 42 & 32.6 & 29 & 34.9 & 11 & 13.3 \\
\hline Trait anxiety & 83 & 53.2 & 79 & 53.7 & 76 & 58.9 & 50 & 60.2 & 25 & 30.1 \\
\hline State anxiety & 94 & 60.3 & 88 & 59.9 & 82 & 63.6 & 53 & 63.9 & 29 & 34.9 \\
\hline Depression and anxiety & 39 & 25.0 & 42 & 28.6 & 40 & 31.0 & 27 & 32.5 & 11 & 13.1 \\
\hline
\end{tabular}

T1: 23 to 28 weeks of gestation; T2: 32 to 36 weeks of gestation; T3: over 36 weeks of gestation; T4: 4 to 6 weeks postpartum.

\subsection{Prediction of Stress and Anxiety on Depressive Symptoms}

As shown in Table 4, all measured variables were significantly correlated with each other at all time points ( $\mathrm{r}$ ranged from 0.35 to $0.91, p<0.001$ for all correlations). In order to decide which demographic variables should be included in the GEE analysis to exclude influences of demographic factors on postpartum depressive symptoms, the Mann-Whitney $\mathrm{U}$ test or Kruskal-Wallis test were done to compare level of depressive symptoms by demographic variables. Results showed that the level of postpartum depressive symptoms differed by parity (Mann-Whitney test $=585.50, p=0.03$ ) and sleep disturbance (MannWhitney test $=442.50, p=0.01$ ) (Table 5). Therefore, parity and sleep disturbance were included in the GEE analysis. As shown in Table 6, depressive symptoms, trait anxiety, 
and state anxiety at $\mathrm{T} 1$; trait anxiety at $\mathrm{T} 2$; and state anxiety at postpartum could predict postpartum depressive symptoms.

Table 4. Correlations between measured variables.

\begin{tabular}{|c|c|c|c|c|c|c|c|c|c|c|c|c|c|c|c|}
\hline Variable & 1 & 2 & 3 & 4 & 5 & 6 & 7 & 8 & 9 & 10 & 11 & 12 & 13 & 14 & 15 \\
\hline \multicolumn{16}{|l|}{$\mathrm{T} 1$} \\
\hline 1. Stress & - & & & & & & & & & & & & & & \\
\hline 2. Trait anxiety & 0.68 & - & & & & & & & & & & & & & \\
\hline 3. State anxiety & 0.66 & 0.84 & - & & & & & & & & & & & & \\
\hline 4. Depressive symptoms & 0.64 & 0.79 & 0.69 & - & & & & & & & & & & & \\
\hline \multicolumn{16}{|l|}{$\mathrm{T} 2$} \\
\hline 5. Stress ${ }^{a}$ & 0.67 & 0.69 & 0.63 & 0.64 & - & & & & & & & & & & \\
\hline 6. Trait anxiety & 0.60 & 0.72 & 0.69 & 0.63 & 0.82 & - & & & & & & & & & \\
\hline 7. State anxiety ${ }^{a}$ & 0.51 & 0.68 & 0.64 & 0.58 & 0.77 & 0.91 & - & & & & & & & & \\
\hline 8. Depressive symptoms & 0.56 & 0.65 & 0.61 & 0.70 & 0.80 & 0.86 & 0.81 & - & & & & & & & \\
\hline \multicolumn{16}{|l|}{$\mathrm{T} 3$} \\
\hline 9. Stress ${ }^{a}$ & 0.63 & 0.65 & 0.60 & 0.62 & 0.78 & 0.71 & 0.70 & 0.69 & - & & & & & & \\
\hline 10. Trait anxiety ${ }^{a}$ & 0.53 & 0.71 & 0.65 & 0.63 & 0.71 & 0.81 & 0.81 & 0.76 & 0.81 & - & & & & & \\
\hline 11. State anxiety ${ }^{a}$ & 0.40 & 0.58 & 0.59 & 0.52 & 0.63 & 0.69 & 0.77 & 0.67 & 0.75 & 0.87 & - & & & & \\
\hline 12. Depressive symptoms & 0.48 & 0.62 & 0.52 & 0.62 & 0.65 & 0.70 & 0.67 & 0.79 & 0.78 & 0.83 & 0.76 & - & & & \\
\hline \multicolumn{16}{|l|}{$\mathrm{T} 4$} \\
\hline 13. Stress & 0.51 & 0.36 & 0.35 & 0.44 & 0.59 & 0.44 & 0.39 & 0.44 & 0.52 & 0.47 & 0.41 & 0.46 & - & & \\
\hline 14. Trait anxiety ${ }^{a}$ & 0.44 & 0.35 & 0.45 & 0.44 & 0.55 & 0.50 & 0.47 & 0.53 & 0.51 & 0.53 & 0.49 & 0.47 & 0.82 & - & \\
\hline 15. State anxiety ${ }^{a}$ & 0.43 & 0.39 & 0.41 & 0.46 & 0.58 & 0.50 & 0.43 & 0.49 & 0.55 & 0.52 & 0.45 & 0.49 & 0.83 & 0.88 & - \\
\hline 16. Depressive symptoms & 0.48 & 0.36 & 0.38 & 0.50 & 0.57 & 0.51 & 0.46 & 0.52 & 0.56 & 0.52 & 0.46 & 0.53 & 0.85 & 0.88 & 0.84 \\
\hline
\end{tabular}

Pearson correlation was performed for the variable that was normally distributed (marked with superscript letter ${ }^{\text {a }}$ ). For variables that were not normally distributed, Spearman's correlation was applied.

Table 5. Comparison of postpartum depressive symptoms by demographic variables.

\begin{tabular}{|c|c|c|c|c|c|}
\hline Variable & $\mathbf{M}$ & SD & Median & $\mathbf{U}$ or $\mathbf{H}$ & $p$ \\
\hline Parity & & & & 594.50 & 0.02 \\
\hline Primiparous & 16.66 & 11.97 & 14.00 & & \\
\hline Multiparous & 10.82 & 8.59 & 8.00 & & \\
\hline Marital status & & & & 1.52 & 0.47 \\
\hline Single & 13.00 & 15.47 & 8.50 & & \\
\hline Married & 14.07 & 10.88 & 12.00 & & \\
\hline others & 21.50 & 10.61 & 21.50 & & \\
\hline Education level & & & & 701.00 & 0.31 \\
\hline Bachelor or higher & 12.96 & 10.26 & 11.00 & & \\
\hline Lower than bachelor & 15.85 & 12.10 & 12.00 & & \\
\hline Employment & & & & 486.00 & 0.40 \\
\hline Unemployed & 11.42 & 10.56 & 11.00 & & \\
\hline Employed & 14.65 & 11.15 & 12.34 & & \\
\hline Planned pregnancy & & & & 658.50 & 0.41 \\
\hline No & 12.32 & 9.66 & 10.00 & & \\
\hline Yes & 15.00 & 11.69 & 12.68 & & \\
\hline Happy about the pregnancy & & & & 0.68 & 0.71 \\
\hline Very unhappy or unhappy & 16.33 & 5.03 & 17.00 & & \\
\hline Very happy or happy & 14.13 & 11.06 & 12.00 & & \\
\hline Uncertain & 13.75 & 15.28 & 10.00 & & \\
\hline Sleep disturbance & & & & 448.50 & 0.01 \\
\hline No & 9.73 & 9.12 & 6.00 & & \\
\hline Yes & 16.15 & 11.36 & 14.00 & & \\
\hline
\end{tabular}

U: Mann-Whitney U test statistic for variable with two levels; H: Kruskal-Wallis H test statistic for variable with more than two levels. 
Table 6. Prediction of perinatal stress and anxiety on postpartum depression.

\begin{tabular}{|c|c|c|c|c|c|}
\hline Variable & B & SE & $95 \%$ CI & Wald $X^{2}$ & $p$ \\
\hline (Intercept) & -19.84 & 2.02 & $-23.81,-15.87$ & 96.03 & $<0.001$ \\
\hline $\begin{array}{c}\text { Depression } \\
\text { T1 }\end{array}$ & -2.52 & 1.11 & $-4.70,-0.34$ & 5.12 & 0.02 \\
\hline $\mathrm{T} 2$ & -1.81 & 1.19 & $-4.14,0.52$ & 2.31 & 0.13 \\
\hline $\mathrm{T} 3$ & -1.65 & 1.12 & $-3.85,0.54$ & 2.12 & 0.14 \\
\hline $\mathrm{T} 4$ & - & & & & \\
\hline Stress T1 & 0.12 & 0.07 & $-0.03,0.26$ & 2.45 & 0.12 \\
\hline $\mathrm{T} 2$ & 0.07 & 0.15 & $-0.23,0.36$ & 0.19 & 0.66 \\
\hline T3 & 0.10 & 0.12 & $-0.14,0.34$ & 0.70 & 0.40 \\
\hline $\mathrm{T} 4$ & -0.11 & 0.09 & $-0.30,0.07$ & 1.41 & 0.23 \\
\hline $\begin{array}{c}\text { Trait anxiety } \\
\text { T1 }\end{array}$ & 0.19 & 0.08 & $0.03,0.34$ & 5.77 & 0.02 \\
\hline $\mathrm{T} 2$ & 0.19 & 0.09 & $0.02,0.37$ & 4.68 & 0.03 \\
\hline T3 & 0.21 & 0.11 & $-0.01,0.43$ & 3.47 & 0.06 \\
\hline $\mathrm{T} 4$ & 0.07 & 0.07 & $-0.06,0.20$ & 1.15 & 0.29 \\
\hline $\begin{array}{c}\text { State anxiety } \\
\mathrm{T} 1\end{array}$ & -0.15 & 0.06 & $-0.27,-0.03$ & 5.54 & 0.02 \\
\hline $\mathrm{T} 2$ & -0.05 & 0.06 & $-0.17,0.08$ & 0.49 & 0.48 \\
\hline T3 & 0.04 & 0.06 & $-0.08,0.17$ & 0.49 & 0.49 \\
\hline $\mathrm{T} 4$ & 0.20 & 0.06 & $0.08,0.32$ & 10.65 & 0.001 \\
\hline Parity & -0.25 & 0.75 & $-1.72,1.23$ & 0.11 & 0.75 \\
\hline $\begin{array}{c}\text { Sleep } \\
\text { disturbance }\end{array}$ & 1.10 & 0.71 & $-0.29,2.50$ & 2.41 & 0.12 \\
\hline
\end{tabular}

\section{Discussion}

This study aims to explore trends and relationships between perinatal depressive symptoms, anxiety, and stress and predictors of postpartum depressive symptoms. We found that the prevalence of depression in the women was over one fourth (ranged from $25.6 \%$ to $34.9 \%$ ), and it increased over the time from pregnancy to postpartum. This result was similar to a study done in German that $27.7 \%$ of mothers self-reported that they felt depressed during pregnancy [18]; one national data analysis in the United States that $35.6 \%$ of Chinese mothers experienced depression [9]; and another study done in Taiwan [38]. However, the rate of depression was higher than that of Chinese women (19.7\% during pregnancy and $14.8 \%$ in postpartum) as reported in Nisar et al.'s [16] metaanalysis article when depression were assessed using the CESD. Despite the difference in the prevalence of depression caused by different assessment tools and study regions, several reasons warrant early detection and management of prenatal depressive symptoms. First, the intensity of depressive symptoms increases over time and significantly increases at 36 weeks gestation and postpartum when the woman is approaching labor/delivery and is about to face the challenge of postpartum physical, psychosocial, and role changes as well as childcare responsibilities. Second, prenatal depressive symptoms can predict postpartum depressive symptoms. Third, depression has negative impacts on both women and their children [14-16,18].

Over half (ranged from $53.2 \%$ to $63.9 \%$ ) of perinatal women experienced anxiety in our study, especially around $60 \%$ of women experienced state anxiety during pregnancy and postpartum. This rate was much higher than the pooled rate of perinatal anxiety symptoms (ranged from $18.2 \%$ to $24.6 \%$ ) and the pooled rate of perinatal trait anxiety (ranged from $29.1 \%$ to $32.5 \%$ ) reported in other studies [11]. Factors causing this high rate of perinatal anxiety in our study sample need further exploration. Regardless, in our study, the intensity of state anxiety significantly increased at T3 when the mother was about to give birth. Since prenatal anxiety is related to a higher risk of birth complications 
and lower Apgar scores in babies [14], and is also significantly correlated with depressive symptoms, as recommended by the American College of Obstetricians and Gynecologists (ACOG), obstetric care providers should screen pregnant women for depressive and anxiety symptoms at least once during pregnancy and postpartum. In particular, a full assessment for postpartum depression and anxiety is recommended [8].

Perceived stress was strongly correlated with anxiety and depressive symptoms during pregnancy and postpartum in our study, which was similar to the few studies that focused on perinatal perceived stress, anxiety, and depressive symptoms $[26,27,38]$. However, in contrast to another study's finding that perceived stress during late pregnancy and early postpartum could predict postpartum depressive symptoms [27], we did not find this prediction in our study. The inconsistency might be due to different countries of study and measuring tools. Nevertheless, the management of perceived stress is warranted because of its strong correlation with perinatal anxiety and depressive symptoms. Other studies, which found that pregnant women with high stress levels had high odds of having probable prenatal depression and that prenatal stress could predict prenatal depressive symptoms and anxiety, [45,46] also highlighted the importance of assessing and managing perinatal stress.

The trend of perceived stress from pregnancy to postpartum found in our study was similar to another longitudinal study done in Taiwan [38] which found that stress levels decreased from 24 weeks to 32 weeks and remained at similar levels at 36 weeks of gestation, but returned to high levels after childbirth. This result was different from another study done in Australia which found that stress levels significantly decreased from 24 weeks to 28 weeks, then increased at 32 weeks and remained about the same at 36 weeks gestation [46]. These results may indicate that during the second trimester, pregnant women may feel a certain degree of relief from discomforts occurring in the first trimester and therefore decreased their stress level. However, after childbirth, new mothers are stressed since they have to face tasks of the maternal role and adapt to physical and psychosocial changes.

\section{Limitation and Suggestion}

This study uses a prospective longitudinal study design that follows pregnant women from 24 weeks gestation until one month postpartum. This design provides a more comprehensive picture of the changing courses of perinatal psychological distress. Despite the strength of the study design, there are limitations. The generalizability of the findings in our study is limited because of the relatively small sample size, high attrition $(46.8 \%$ from T1 to T4), studying only in metropolitan cities, and using self-reported measurements rather than diagnostic interviews to assess mental disorders. Although post-hoc power analysis showed a high power, which showed an adequate sample size to detect effects of significance, we recommend conducting more longitudinal studies that include more pregnant women from cities in various stages of urban development. While conducting longitudinal studies, in addition to frequent contacts with the participants, reminder calls, data collected in clinic when participants arrived for checkups, and monetary incentives done in our study, it is recommended to apply strategies that show effectiveness in improving retention rates, such as using social media, using alternative methods of data collection, sending thank-you cards, and offering home visits [47].

\section{Conclusions}

The purpose of this longitudinal study is to explore trends of stress, anxiety, and depressive symptoms from pregnancy to postpartum and understand predictions of stress and anxiety on postpartum depression. We found that levels of anxiety and depressive symptoms increase from 24 weeks gestation to postpartum, whereas stress levels decrease during pregnancy but increase in postpartum. While over one fourth of women experience perinatal depressive symptoms, over half of women experience anxiety symptoms especially during late pregnancy and postpartum. More than one fourth of women were both 
depressed and anxious at some point of time during pregnancy and postpartum. Stress, anxiety, and depressive symptoms are significantly inter-correlated among four measuring time points. Notably, women at late pregnancy and postpartum are prone to stress, anxiety, and depression. Prenatal anxiety can predict postpartum depressive symptoms. Based on the study results, we suggest actively assessing women's stress, anxiety, and depression beginning from early pregnancy and continuing until postpartum. We also suggest providing interventions that showed effectiveness in managing perinatal stress, anxiety, and depression to women especially at late pregnancy and postpartum period. This includes mindfulness-based childbirth and parenting programs that has significant effects in reducing perceived stress and depressive symptoms [48], internet-delivered cognitive behavioral therapy and internet-delivered behavioral activation interventions that can significantly improve perinatal depression and anxiety [49], online support, peer experiences sharing, and perinatal anxiety-related psychoeducation, which are recommended by women experiencing perinatal anxiety [50]. Care needs to be provided especially to women who are at high risk of experiencing perinatal mental distress due to certain factors: young, single or not partnered, low literacy, low socioeconomic status, having relationships or social support, experiencing prior miscarriage or perinatal loss, low self-esteem, past depression, lower income level, and higher stress [26,51].

Supplementary Materials: The following are available online at https:/ / www.mdpi.com/article/10 .3390/ijerph18179307/s1.

Author Contributions: Conceptualization, C.-Y.C., Y.-H.C., and S.-R.L.; methodology, C.-Y.C. and S.-R.L.; validation, C.-Y.C. and Y.-H.C.; formal analysis, C.-Y.C. and C.-H.C.; investigation, C.-Y.C. and Y.-H.C.; resources, C.-Y.C. and S.-R.L.; data curation, C.-Y.C. and C.-H.C.; writing-original draft preparation, C.-Y.C., C.-H.C., and S.-R.L.; writing-review and editing, C.-Y.C., Y.-H.C. and S.-R.L.; supervision, C.-Y.C. and S.-R.L.; project administration, C.-Y.C. and S.-R.L.; funding acquisition, C.-Y.C. and S.-R.L. All authors have read and agreed to the published version of the manuscript.

Funding: This research was funded by Chang Gung Medical Foundation, CMRPF6130011 and CMRPF6130012.

Institutional Review Board Statement: The study was conducted according to the guidelines of the Declaration of Helsinki and approved by the Institutional Review Board of Chang Gung Memorial Hospital (protocol code 100-2777A3, 18 November 2011) and Chia-Yi Christian Hospital (protocol code 101073, 27 November 2011).

Informed Consent Statement: Informed consent was obtained from all subjects involved in the study.

Data Availability Statement: The data set is available online at https:/ / data.mendeley.com/datasets / r37922phfd/1 (accessed on 2 September 2021).

Conflicts of Interest: The authors declare no conflict of interest.

\section{References}

1. James, S.L.; Abate, D.; Abate, K.H.; Abay, S.M.; Abbafati, C.; Abbasi, N.; Abbastabar, H.; Abd-Allah, F.; Abdela, J.; Abdelalim, A.; et al. Global, regional, and national incidence, prevalence, and years lived with disability for 354 diseases and injuries for 195 countries and territories, 1990-2017: A systematic analysis for the Global Burden of Disease Study 2017. Lancet 2018, 392, 1789-1858. [CrossRef]

2. Kuehner, C. Why is depression more common among women than among men? Lancet Psychiatry 2017, 4, 146-158. [CrossRef]

3. Labaka, A.; Goñi-Balentziaga, O.; Lebeña, A.; Pérez-Tejada, J. Biological sex differences in depression: A systematic review. Biol. Res. Nurs. 2018, 20, 383-392. [CrossRef] [PubMed]

4. Lim, G.Y.; Tam, W.W.; Lu, Y.; Ho, C.S.; Zhang, M.W.; Ho, R. Prevalence of depression in the community from 30 countries between 1994 and 2014. Sci. Rep. 2018, 8, 1-10. [CrossRef]

5. Soares, C.N.; Zitek, B. Reproductive hormone sensitivity and risk for depression across the female life cycle: A continuum of vulnerability? J. Psychiatry. Neurosci. 2008, 33, 331-343. [PubMed]

6. Bennett, H.A.; Einarson, A.; Taddio, A.; Koren, G.; Einarson, T.R. Prevalence of depression during pregnancy: Systematic review. Obstet. Gynecol. 2004, 103, 698-709. [CrossRef]

7. Hahn-Holbrook, J.; Cornwell-Hinrichs, T.; Anaya, I. Economic and health predictors of national postpartum depression prevalence: A systematic review, meta-analysis, and meta-regression of 291 studies from 56 countries. Front. Psychiatry 2018, 8, 248. [CrossRef] 
8. ACOG Committee. ACOG Committee Opinion No. 757: Screening for perinatal depression. Obstet. Gynecol. 2018, 132, e208-e212. [CrossRef]

9. Huang, Z.J.; Wong, F.Y.; Ronzio, C.R.; Yu, S.M. Depressive symptomatology and mental health help-seeking patterns of U.S.- and foreign-born mothers. Matern. Child Health J. 2007, 11, 257-267. [CrossRef]

10. Barker, E.D.; Jaffee, S.R.; Uher, R.; Maughan, B. The contribution of prenatal and postnatal maternal anxiety and depression to child maladjustment. Depress. Anxiety 2011, 28, 696-702. [CrossRef]

11. Dennis, C.-L.; Falah-Hassani, K.; Shiri, R. Prevalence of antenatal and postnatal anxiety: Systematic review and meta-analysis. Br. J. Psychiatry 2017, 210, 315-323. [CrossRef] [PubMed]

12. Zhang, L.; Wang, L.; Cui, S.; Yuan, Q.; Huang, C.; Zhou, X. Prenatal depression in women in the third trimester: Prevalence, predictive factors, and relationship with maternal-fetal attachment. Front. Public Health 2021, 8, 602005. [CrossRef] [PubMed]

13. Sleath, B.; West, S.; Tudor, G.; Perreira, K.; King, V.; Morrissey, J. Ethnicity and prenatal depression: Women's experiences and perspectives on communicating about their emotions and feelings during pregnancy. Patient Educ. Couns. 2005, 58, 35-40. [CrossRef]

14. Dowse, E.; Chan, S.; Ebert, L.; Wynne, O.; Thomas, S.; Jones, D.; Fealy, S.; Evans, T.-J.; Oldmeadow, C. Impact of perinatal depression and anxiety on birth outcomes: A retrospective data analysis. Matern. Child Health J. 2020, 24, 718-726. [CrossRef]

15. Li, X.; Gao, R.; Dai, X.; Liu, H.; Zhang, J.; Liu, X.; Si, D.; Deng, T.; Xia, W. The association between symptoms of depression during pregnancy and low birth weight: A prospective study. BMC Pregnancy Childbirth 2020, 20, 1-7. [CrossRef] [PubMed]

16. Nisar, A.; Yin, J.; Waqas, A.; Bai, X.; Wang, D.; Rahman, A.; Li, X. Prevalence of perinatal depression and its determinants in Mainland China: A systematic review and meta-analysis. J. Affect. Disord. 2020, 277, 1022-1037. [CrossRef]

17. Choi, K.W.; Houts, R.; Arseneault, L.; Pariante, C.M.; Sikkema, K.J.; Moffitt, T. Maternal depression in the intergenerational transmission of childhood maltreatment and its sequelae: Testing postpartum effects in a longitudinal birth cohort. Dev. Psychopathol. 2019, 31, 143-156. [CrossRef]

18. Zohsel, K.; Holz, N.E.; Hohm, E.; Schmidt, M.H.; Esser, G.; Brandeis, D.; Banaschewski, T.; Laucht, M. Fewer self-reported depressive symptoms in young adults exposed to maternal depressed mood during pregnancy. J. Affect. Disord. 2017, 209, 155-162. [CrossRef]

19. Rogers, A.; Obst, S.; Teague, S.J.; Rossen, L.; Spry, E.A.; Macdonald, J.A.; Sunderland, M.; Olsson, C.A.; Youssef, G.; Hutchinson, D. Association between maternal perinatal depression and anxiety and child and adolescent development: A meta-analysis. JAMA Pediatr. 2020, 174, 1082-1092. [CrossRef]

20. Mancuso, R.A.; Schetter, C.D.; Rini, C.M.; Roesch, S.C.; Hobel, C.J. Maternal prenatal anxiety and corticotrophin-releasing hormone associated with timing of delivery. Psychosom. Med. 2004, 66, 762-769. [CrossRef]

21. Britton, J.R. Postpartum anxiety and breast feeding. J. Reprod. Med. 2007, 52, 689-695. [PubMed]

22. Polte, C.; Junge, C.; Von Soest, T.; Seidler, A.; Eberhard-Gran, M.; Garthus-Niegel, S. Impact of maternal perinatal anxiety on social-emotional development of 2-year-olds, a prospective study of Norwegian mothers and their offspring: The impact of perinatal anxiety on child development. Matern. Child Health J. 2019, 23, 386-396. [CrossRef] [PubMed]

23. Luca, D.L.; Margiotta, C.; Staatz, C.; Garlow, E.; Christensen, A.; Zivin, K. Financial toll of untreated perinatal mood and anxiety disorders among 2017 births in the United States. Am. J. Public Health 2020, 110, 888-896. [CrossRef] [PubMed]

24. Rees, S.; Channon, S.; Waters, C.S. The impact of maternal prenatal and postnatal anxiety on children's emotional problems: A systematic review. Eur. Child Adolesc. Psychiatry 2019, 28, 257-280. [CrossRef] [PubMed]

25. Field, T.; Diego, M.; Hernandez-Reif, M.; Figueiredo, B.; Deeds, O.; Ascencio, A.; Schanberg, S.; Kuhn, C. Comorbid depression and anxiety effects on pregnancy and neonatal outcome. Infant Behav. Dev. 2010, 33, 23-29. [CrossRef]

26. Ahmed, A.; Feng, C.; Bowen, A.; Muhajarine, N. Latent trajectory groups of perinatal depressive and anxiety symptoms from pregnancy to early postpartum and their antenatal risk factors. Arch. Women Ment. Health 2018, 21, 689-698. [CrossRef]

27. Razurel, C.; Kaiser, B.; Antonietti, J.-P.; Epiney, M.; Sellenet, C. Relationship between perceived perinatal stress and depressive symptoms, anxiety, and parental self-efficacy in primiparous mothers and the role of social support. Women Health 2017, 57, 154-172. [CrossRef]

28. Torres, R.; Goyal, D.; Burke-Aaronson, A.C.; Gay, C.L.; Lee, K.A. Patterns of symptoms of perinatal depression and stress in late adolescent and young adult mothers. J. Obstet. Gynecol. Neonatal Nurs. 2017, 46, 814-823. [CrossRef]

29. Abeysena, C.; Jayawardana, P.; Seneviratne, R.D.A. Effect of psychosocial stress on maternal complications during pregnancy: A cohort study. Int. J. Collab. Res. Intern. Med. Public Health 2010, 2, 436-448.

30. Roy-Matton, N.; Moutquin, J.-M.; Brown, C.; Carrier, N.; Bell, L. The impact of perceived maternal stress and other psychosocial risk factors on pregnancy complications. J. Obstet. Gynaecol. Can. 2011, 33, 344-352. [CrossRef]

31. Insaf, T.; Fortner, R.; Pekow, P.; Dole, N.; Markenson, G.; Chasan-Taber, L. Prenatal stress, anxiety, and depressive symptoms as predictors of intention to breastfeed among hispanic women. J. Women Health 2011, 20, 1183-1192. [CrossRef]

32. Tegethoff, M.; Greene, N.; Olsen, J.; Schaffner, E.; Meinlschmidt, G. Stress during pregnancy and offspring pediatric disease: A national cohort study. Environ. Health Perspect. 2011, 119, 1647-1652. [CrossRef]

33. Faul, F.; Erdfelder, E.; Lang, A.-G.; Buchner, A. G*Power 3: A flexible statistical power analysis program for the social, behavioral, and biomedical sciences. Behav. Res. Methods 2007, 39, 175-191. [CrossRef]

34. Steyn, H.S., Jr.; Ellis, S.M. Estimating an effect size in one-way multivariate analysis of variance (MANOVA). Multivar. Behav. Res. 2009, 44, 106-129. [CrossRef] 
35. Radloff, L.S. The CES-D Scale: A self-report depression scale for research in the general population. Appl. Psychol. Meas. 1977, 1, 385-401. [CrossRef]

36. Cheng, C.-Y.; Pickler, R.H. Effects of stress and social support on postpartum health of Chinese mothers in the United States. Res. Nurs. Health 2009, 32, 582-591. [CrossRef] [PubMed]

37. Cohen, S.; Williamson, G.M. Perceived stress in a probability sample of the United States. The Social Psychology of Health; Spacepan, S., Oskamp, S., Eds.; Sage: Newbury Park, CA, USA, 1988; pp. 31-67.

38. Liou, S.-R.; Wang, P.; Cheng, C.-Y. Longitudinal study of perinatal maternal stress, depressive symptoms and anxiety. Midwifery 2014, 30, 795-801. [CrossRef]

39. Spielberger, C.-D. State-Trait Anxiety Inventory for Adults ${ }^{\mathrm{TM}}$. Mind Garden Inc.: Menlo Park, CA, USA. Available online: https:/ / www.mindgarden.com/145-state-trait-anxiety-inventory-for-adults (accessed on 2 September 2021).

40. Gunning, M.; Denison, F.; Stockley, C.; Ho, S.; Sandhu, H.; Reynolds, R. Assessing maternal anxiety in pregnancy with the State-Trait Anxiety Inventory (STAI): Issues of validity, location and participation. J. Reprod. Infant. Psychol. 2010, 28, 266-273. [CrossRef]

41. Grant, K.-A.; McMahon, C.; Austin, M.-P. Maternal anxiety during the transition to parenthood: A prospective study. J. Affect. Disord. 2008, 108, 101-111. [CrossRef] [PubMed]

42. Shek, D. Reliability and factorial structure of the Chinese version of the state-trait anxiety inventory. J. Psychopathol. Behav. Assess. 1988, 10, 303-317. [CrossRef]

43. Li, C. Little's test of missing completely at random. Stata J. Promot. Commun. Stat. Stata 2013, 13, 795-809. [CrossRef]

44. Little, R.J.A. A test of missing completely at random for multivariate data with missing values. J. Am. Stat. Assoc. 1988, 83, 1198-1202. [CrossRef]

45. Gokoel, A.R.; Wahid, F.A.; Zijlmans, W.C.W.R.; Shankar, A.; Hindori-Mohangoo, A.D.; Covert, H.H.; MacDonald-Ottevanger, M.-S.; Lichtveld, M.Y.; Harville, E.W. Influence of perceived stress on prenatal depression in Surinamese women enrolled in the CCREOH study. Reprod. Health 2021, 18, 1-10. [CrossRef] [PubMed]

46. Rallis, S.; Skouteris, H.; McCabe, M.; Milgrom, J. A prospective examination of depression, anxiety and stress throughout pregnancy. Women Birth 2014, 27, e36-e42. [CrossRef]

47. Teague, S.; the SEED Lifecourse Sciences Theme; Youssef, G.J.; Macdonald, J.A.; Sciberras, E.; Shatte, A.; Fuller-Tyszkiewicz, M.; Greenwood, C.; McIntosh, J.; Olsson, C.A.; et al. Retention strategies in longitudinal cohort studies: A systematic review and meta-analysis. BMC Med Res. Methodol. 2018, 18, 151. [CrossRef] [PubMed]

48. Lönnberg, G.; Jonas, W.; Unternaehrer, E.; Bränström, R.; Nissen, E.; Niemi, M. Effects of a mindfulness based childbirth and parenting program on pregnant women's perceived stress and risk of perinatal depression-Results from a randomized controlled trial. J. Affect. Disord. 2020, 262, 133-142. [CrossRef]

49. Loughnan, S.A.; Joubert, A.E.; Grierson, A.; Andrews, G.; Newby, J. Internet-delivered psychological interventions for clinical anxiety and depression in perinatal women: A systematic review and meta-analysis. Arch. Women Ment. Health 2019, 22, 737-750 [CrossRef] [PubMed]

50. Harrison, V.; Moore, D.; Lazard, L. Supporting perinatal anxiety in the digital age; a qualitative exploration of stressors and support strategies. BMC Pregnancy Childbirth 2020, 20, 1-20. [CrossRef]

51. Fawcett, E.J.; Fairbrother, N.; Cox, M.L.; White, I.; Fawcett, J.M. The prevalence of anxiety disorders during pregnancy and the postpartum period: A multivariate Bayesian meta-analysis. J. Clin. Psychiatry 2019, 80, 18r12527. [CrossRef] 